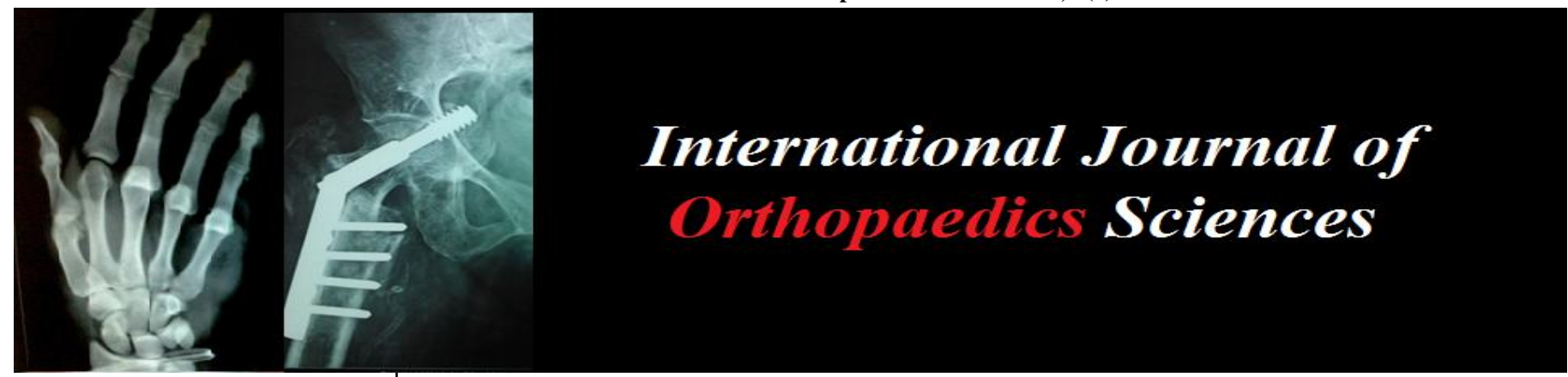

ISSN: $2395-1958$

IJOS 2017; 3(4): 840-844

(C) 2017 IJOS

www.orthopaper.com

Received: 24-08-2017

Accepted: 25-09-2017

Dr. Sandeep Kubsad D’Ortho, DNB (Ortho), Assistant Professor, Department of Orthopaedics, Subbaiah Institute of Medical Sciences, Shivamogga, Karnataka, India

Dr. Suresha B

D'Ortho, DNB (Ortho),

Assistant Professor, Department

of Orthopaedics, Subbaiah

Institute of Medical Sciences,

Shivamogga, Karnataka, India

Dr. Harish S Pai

M.S Ortho, Professor and HOD,

Department of Orthopaedics,

Subbaiah Institute of Medical

Sciences, Shivamogga,

Karnataka, India

Dr. Bharath SG

M.S Ortho, Assistant Professor,

Department of Orthopaedics,

Subbaiah Institute of Medical

Sciences, Shivamogga,

Karnataka, India

Dr. Manohar Reddy

DNB Ortho, Senior Resident,

Department of Orthopaedics,

Subbaiah Institute of Medical

Sciences, Shivamogga,

Karnataka, India
Correspondence

Dr. Sandeep Kubsad

D'Ortho, DNB (Ortho),

Assistant Professor, Department

of Orthopaedics, Subbaiah

Institute of Medical Sciences,

Shivamogga, Karnataka, India

\section{Functional evaluation of comminuted inferior pole patella treated by excision of comminuted fragment and trans-osseous fixation of patellar tendon using non- absorbable suture}

\author{
Dr. Sandeep Kubsad, Dr. Suresha B, Dr. Harish S Pai, Dr. Bharath SG \\ and Dr. Manohar Reddy
}

DOI: $\underline{\text { https://doi.org/10.22271/ortho.2017.v3.i4l.114 }}$

\section{Abstract}

Inferior pole fracture accounts for only $20 \%$ of surgically treated patellar fractures. The treatment option for inferior pole patella fracture is still being debated. In our study we treated comminuted inferior pole patella fracture by excision of the comminuted fragment and transosseous fixation of patellar tendon by using Ethibond No. 5. Among 10 patients who were retrospectively studied, excellent and good results were found in 9 out of 10 patients according Gaur's criteria for knee evaluation.

Hence we concluded that for comminuted inferior pole patella fractures, excision of the fragments and transosseous fixation of patellar tendon to the proximal patella is a very effective treatment method.

Keywords: Inferior pole fracture patella, excision of inferior pole, transosseous fixation

\section{Introduction}

Patella fractures comprise $1 \%$ of all fractures encountered in the emergency department, and only a third of these require surgical interventions ${ }^{[1,2]}$. Among patellar fractures treated surgically, approximately $20 \%$ involve the inferior pole ${ }^{[3]}$. Fracture of the distal pole of patella usually are less than $1.5 \mathrm{~cm}$ in vertical height, extraarticularly located and most of the time comminuted. Because of this, treating this type of fracture poses a special problem ${ }^{[4,5]}$.

Various treatment options include tension band wiring (TBW), circumferential wiring, cancellous screws fixation, fixation of the lower pole augmented by patellotibial SS wire loop, basket loop fixation and excision of the lower pole of the patella ${ }^{[6,7]}$.

The superior fragment is important for effective extensor mechanism and to be preserved. The reattachment of the patellar tendon to the proximal cancellous rough surface of fracture patella is controversial. Some trauma surgeons recommended attachment of the patellar tendon near the articular surfaces and others advocate reattachment near the anterior cortex ${ }^{[4]}$.

We studied 10 cases of inferior pole comminuted patella fracture treated by excision of comminuted avulsed fragment and transosseous repair of patellar tendon using Ethibond No.5 suture material.

\section{Methods and materials}

A retrospective study of three year period from August 2013-August 2016 at Subbaiah institute of medical college, Shivamogga. 45 patients with fracture patella were treated operatively in our institution. Among them 11 cases was comminuted lower pole patella fracture. 1 case was excluded from the study due to lack of follow up. All patients presented to our hospital between day 1 to day 5. Initially above knee posterior slab was given. All patients were operated within 1 week. Ethical committee clearance was taken before the start of study. Patients with ipsilateral lower limb fractures and open wounds were excluded from the study.

\subsection{Surgical technique}

Patient positioned supine on radiolucent table. IV antibiotics injection cefotaxime $1 \mathrm{gm}$ was given preoperatively. In all patients spinal anaesthesia was given and pneumatic tourniquet was used. 
2.1.1 Surgical Approach: Anterior midline incision from superior pole of patella up to tibial tuberosity was made, full thickness skin flaps were raised medially and laterally to expose the fracture fragments (Figure 1.a). Saline irrigation done and the comminuted inferior pole pieces were excised (Figure 1.b). In inferior pole fracture, comminution is common and care is taken to preserve soft tissue attachment of patellar tendon. Three vertical drill holes were made using $2.5 \mathrm{~mm}$ drill through the articular margin of proximal fragment and directed to the antero-superior border of patella keeping knee in flexion (Figure 1.c). Patellar tendon was sutured by Krackow technique weaving through medial and lateral half of patella, four strands of sutures was passed transosseously with beath needle (Figure 1.d) (one on either side and two in the central hole), next sutures held on the superior pole of patella and knee flexion checked up to $90^{\circ}$ before tying a knot (Figure 1.e). With the knee held in extension, sutures were secured onto the superior pole patella (Figure 1.f). The patellar tendon was slightly everted and made to lie against the raw fractured surface of the patellar remnants near articular surface. This prevents the tilting of patellar fragment and prevents contacting of raw surface of patella with femur ${ }^{[8]}$. Then retinacular tears were repaired using 1-0 vicryl. Knee flexion was checked at this time, the average flexion achieved on table was 90 degree. The wound was again washed with normal saline and wound closed in layers with a drain and knee immobiliser.

Drain was removed on second post-op day and X-rays were taken (Figure 2.b). Postoperatively patient was encouraged to do isometric quadriceps exercises and ankle movements and non-weight bearing with crutches. Under physiotherapist supervision, gradual knee mobilising exercises were started after 4 weeks and the partial weight bearing with crutches was started, and then gradually discontinued. Patients were regularly followed up for 2 years (4 weeks, 8 weeks, 12 weeks, 6 months, 1 year and 2 years). (Figure 3.a and 3.b).

\section{Results}

The patients were followed up for 2 years. There were 8 male and 2 female patients. The average age was between 24 years to 48 years with mean age of 36.8 years. All of them had closed fracture, 2 patients had superficial abrasions. One had superficial wound infection, which was settled down by 2 weeks.

The outcome was assessed by Gaur criteria knee score evaluation (Table. 1) ${ }^{[9]}$. Finally, results were graded as excellent in 5, good in 4 and fair in 1 (Table. 2).

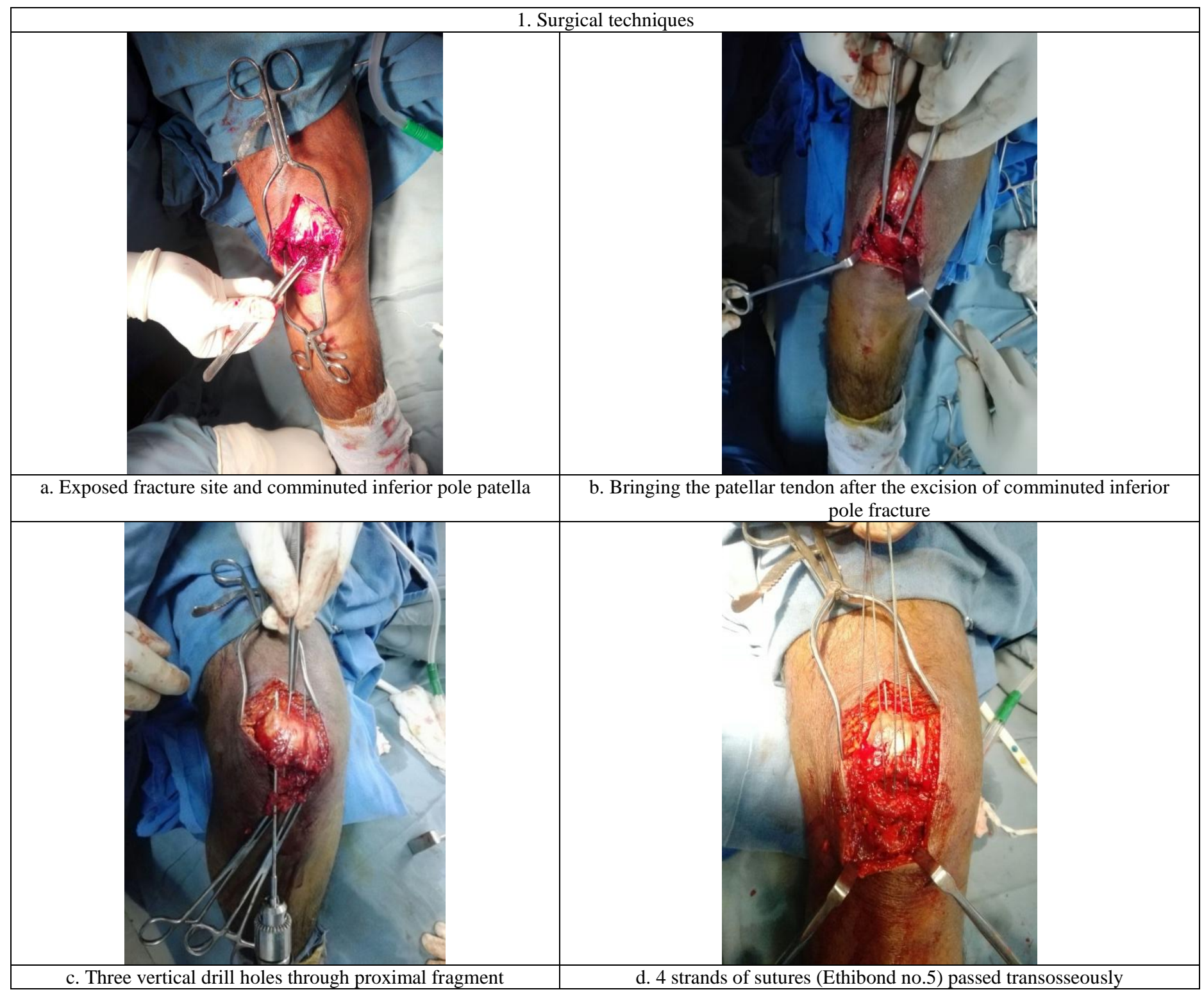



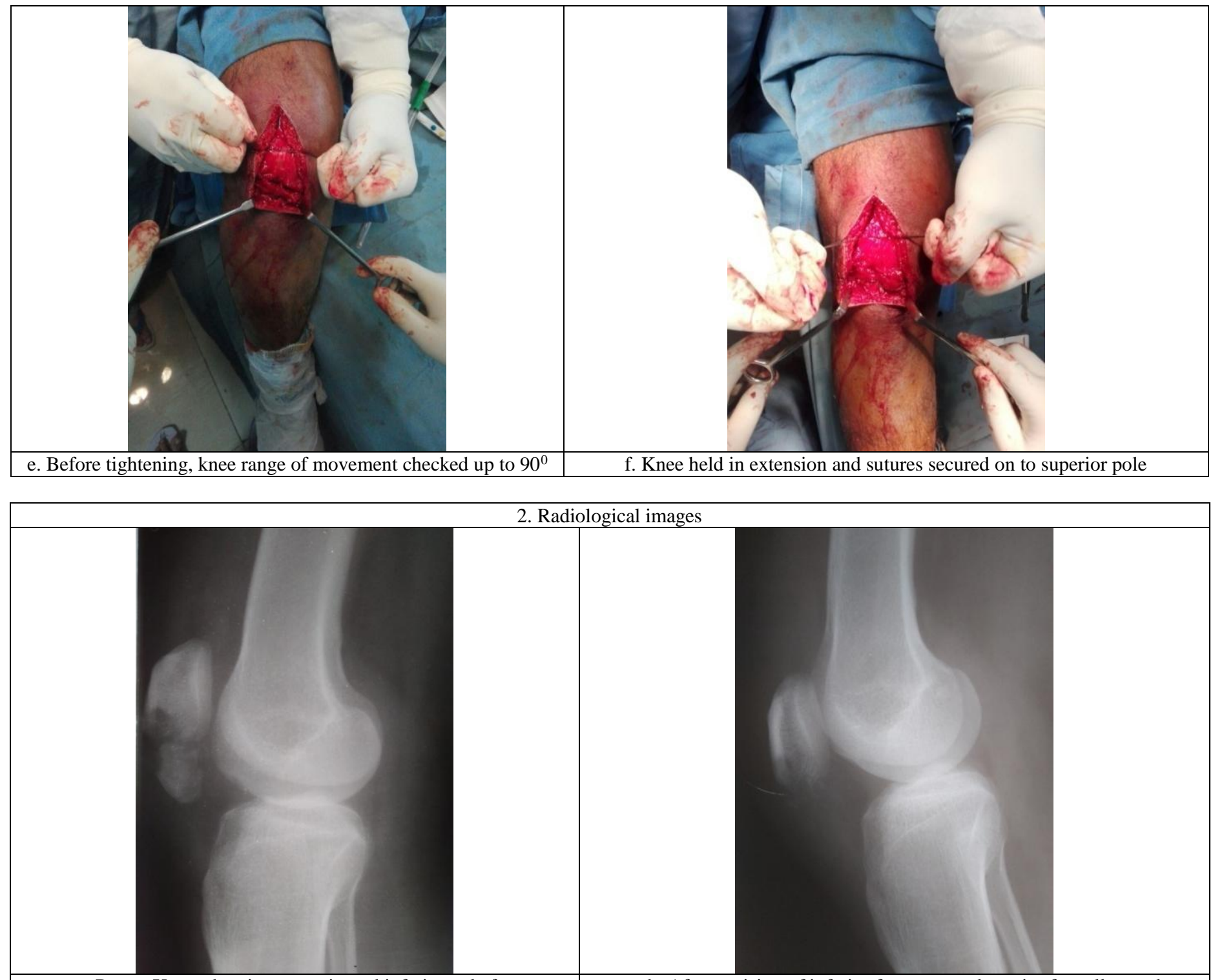

a. Pre op X-ray showing comminuted inferior pole fracture

b. After excision of inferior fragment and repair of patellar tendon

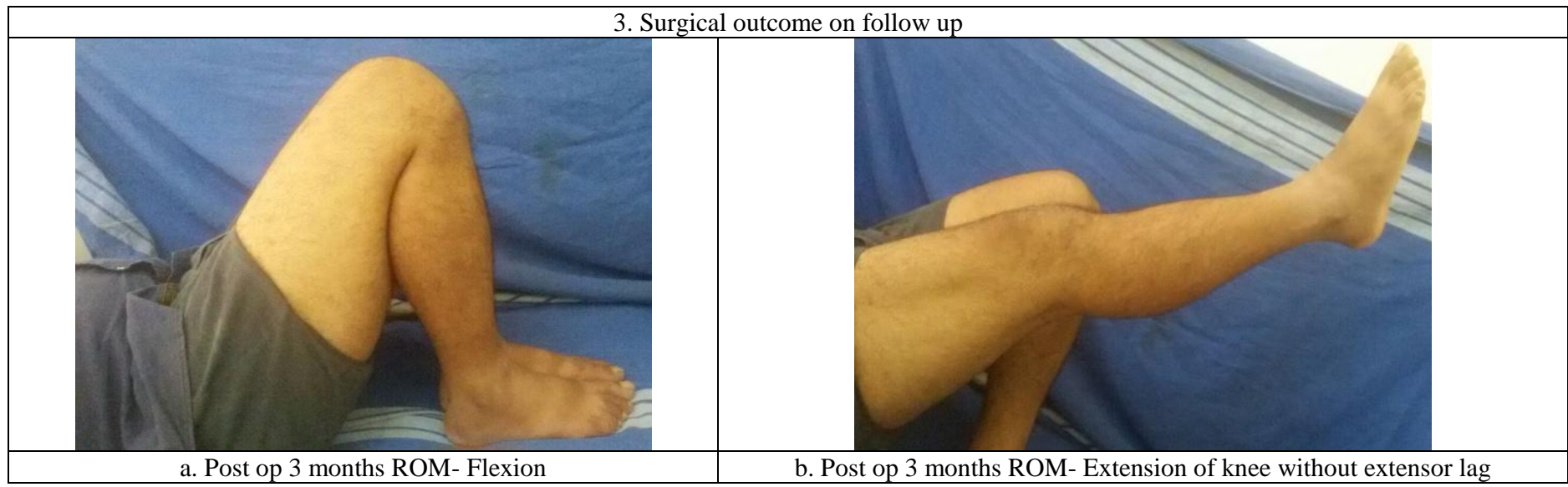

Table 1: Gaur's criteria for knee score evaluation.

\begin{tabular}{|c|c|c|c|c|}
\hline \multirow{2}{*}{ Parameters } & \multicolumn{4}{|c|}{ Result } \\
\cline { 2 - 5 } & Excellent & Good & Fair & Poor \\
\hline Quadriceps wasting & Nil & $<1.5 \mathrm{~cm}$ & Upto $2.5 \mathrm{~cm}$ & $>2.5 \mathrm{~cm}$ \\
\hline Quadriceps power loss & Nil & $<10 \%$ & Up to $25 \%$ & $>25 \%$ \\
\hline Extension lag & No & No & $<10$ & $>10$ \\
\hline Knee ROM & Full & $0-110$ & Up to 90 & $<90$ \\
\hline Knee pain & No & Min & Moderate & Severe \\
\hline Function & Normal & Normal & Restricted & Incapacitated \\
\hline
\end{tabular}


Table 2: Our results

\begin{tabular}{|c|c|c|c|c|}
\hline \multirow{2}{*}{ Parameters } & \multicolumn{4}{|c|}{ Result ( no of patients ) } \\
\cline { 2 - 5 } & Excellent & Good & Fair & Poor \\
\hline Quadriceps wasting & 4 & 5 & 1 & 0 \\
\hline Quadriceps power loss & 5 & 4 & 1 & 0 \\
\hline Extension lag & 6 & 3 & 1 & 0 \\
\hline Knee ROM & 3 & 6 & 1 & 0 \\
\hline Knee pain & 7 & 2 & 1 & 0 \\
\hline Function & 6 & 3 & 1 & 0 \\
\hline
\end{tabular}

\section{Discussion}

The inferior pole patella is an anterior cortical extension and is devoid of articular cartilage. Many studies about resection of distal pole have proved clinically and biochemically that there is shortening of lever arm of extension mechanism ${ }^{[10]}$. According to Huang $\mathrm{HC}$ et al, fixation of inferior pole with $\mathrm{K}$-wire leads to re-operation rates between $20 \%$ to $50 \%$ and further restriction of knee joint range of motion develops. The inherent weakness of the bone and the size of fragments prevent rigid fixation by ordinary wiring or screws [11]. Presently the ideal treatment for avulsed comminuted fractures of the inferior pole has yet to be distinguished. The options include internal fixation of the pole fragment, resection of the avulsed fragment, and repair of the patellar tendon to the patella. According to Chang et al different metal implants used to treat comminuted fracture inferior pole patella usually fails and further restricts movements ${ }^{[12]}$.

Excision of the fragments of bone with attachment of the patellar tendon by transosseous pull-out sutures is usually indicated when fragments are severely comminuted ${ }^{[13]}$.

Kastelec and Veselko, treated 14 patients with inferior pole resection and patellar tendon reattachment, and immobilized in cast for five to seven weeks (mean 6.5 weeks). But in other group treated by internal fixation with basket plate, where early knee mobilisation started and had better results ${ }^{[14]}$.

Availability of basket plate and cost of the implant is high and hence we deferred that. Although mobilization was delayed in our study by 4 weeks, final outcome was good.

Many authors have suggested that, the construct of patellar tendon repair may be protected with a circlage wire, a tendon graft, or a Mersilene tape that is passed immediately proximal to the superior pole of the patella and inferiorly through the proximal tibia posterior to the tibial tubercle. Rigid constructs may allow for early, controlled motion of the knee ${ }^{[10]}$. The disadvantage of using circlage wire is that they create additional stress risers in the patella and tibial tubercle, secondly hardware related problems.

Recently, improved suture material and bone anchor technique have provided sufficient strength for early mobilization after patellar tendon repair, as shown both in biochemical studies and clinical applications. However, bone anchors are not recommended for inferior pole avulsion fractures, because the purchase of a bone anchors depends on having an intact cortex and quality of bone ${ }^{[15]}$.

In our study we used Ethicon No.5 suture material which is non-absorbable, high molecular weight, long chain linear polyester and features unique braid configuration. Ethibond No.5 suture material offers high knot breaking strength, and superior strength. Gunal et al concluded that the core suture technique was the most important element in establishing both strength and stiffness of the repair ${ }^{[16]}$. We didn't use any other additional supporting construct like wires or fibre tape. But post operatively immobilization for 4 weeks fastens the extensor retinacular healing and bone to tendon healing.

Our study can be comparable to B. Punithavasanthan et al study ${ }^{[17]}$. Excellent and good results were achieved in 9 out 10 patients.

Advantages of our study: cost effective, no hardware irritation and removal, easy surgical technique.

\section{Limitations}

Our study was limited to a single institution, less number of patients; no control groups. Long term follow up is required to know the effect on patellofemoral joint.

\section{Conclusion}

Our method of treatment for excision of the communited distal pole and transosseous repair of patellar tendon with Krackow suture using Ethibond No.5 for comminuted inferior pole fracture patella is very effective. The functional outcome was good to excellent and cost effective, but patient compliance is required. Further long term follow up is necessary.

\section{References}

1. Bostrom A. Fracture of the patella.A study of 422 patellar fractures. 1972/01/01 ed, 1972.

2. Lotke PA, Ecker ML. Transerse fractures of the patella. Clin Orthop Relat Res, 1981, 180-4.

3. Neumann HS, Winckler S, Strobel M. Long-term results of surgical management of patellar fractures. Unfallchirurg, 1993; 96:305-10.

4. Cary Fletcher. Comminuted Fractures of the lower pole of the patella - to fix or resect? A case report and review of the literature. EC orthopaedics, 2015; 2(1):54-9.

5. Joshi RR, Dwivedi R, Byanjanakar S, Shrestha R. Outcome of inferior patella pole avulsion fractures: a comparative study. Journal of Lumbini Medical College. 2016; 4(2):84-9. doi:10.22502/jlmc.v4i2.97.

6. Whittle AP. Fractures of Lower extremity. In: Canale ST, Beaty JH, editors. Campbells Operative Orthopedics. 11th ed. St Louis: Mosby. 2008; 3:3161-9.

7. Anand A, Kumar M, Kodikal G. Role of sutures anchors in management of fractures of inferior pole of patella. Indian J orthop. 2010; 44(3):333-5.

8. Patel VR, Parks BG, Wang Y et al. fixation of patella fractures with braided polyester sutures: a biomechanical study, injury, 2000; 31:1.

9. Gaur SC, Verma AN, Kulshrestra, Katiyan AK, Sinha RK. Late outcome of patellectomy. Ind Journal Orthop. 1997; 33(2):422-6.

10. Johnson EE. Fractures of the patella. In: Rockwood CA, Green DP, editors. Fracture of Adults. 6th ed. Philadelphia: Lippincott William, 2006; 2:1956-72.

11. Huang HC, Su JY, Cheng YM. Modified basket plate for inferior patellar pole avulsion fracture - a report of three cases. Kaoshing J Med Sci. 2012; 28(11):619-23.

12. Chang SM, XL JL. Open reduction and internal fixation of displaced patella inferior pole fractures with anterior tension band wiring through cannulated screws. J Orthop 
Trauma. 2011; 25(6):366-70.

13. Saltzman CL, Goulet JA, McClellan RT, Schneider LA, Matthews LS. Results of treatment of displaced patellar fractures by partial patellectomy. J Bone Joint Surg Am. 1990; 72(9):1279-85.

14. Kastelec M, Veselko M. Inferior patellar pole avulsion fractures: osteosynthesis compared with pole resection. J Bone Joint Surg Am. 2004; 86-A(4):696-701.

15. Yang KH, Byun YS. Separate vertical wiring for the fixation of comminuted fractures of the inferior pole of the patella. J Bone Joint surg. 2003; 85B:155.

16. Gunal I, Karatsoun V. Patellectomy: An overview with reconstructive procedures, Clin Orthop Relat Res. 2001; 389:74.

17. Punithavasanthan B et al. Treatment of Comminuted Fracture of Inferior Pole of Patella Using Partial Patellectomy And Patellar Tendon Repair Using Transosseous Sutures. IOSR Journal of Dental and Medical Sciences (IOSR-JDMS) e-ISSN: 2279-0853, pISSN: 2279-0861. 2017; 16(6)VI:PP 34-37. 